\title{
Espiritualidade e resiliência: relevância e implicações no pensamento frankliano
}

\section{Spirituality and resilience: relevance and implications from Franklian thought}

\author{
Josilene Silva da Cruz* \\ Thiago Antonio Avellar de Aquino**
}

\begin{abstract}
Resumo: O presente artigo teve por objetivo identificar a relevância e as implicaçóes dos constructos espiritualidade e resiliência no pensamento de Viktor Frankl. Para tanto, tendo por base as principais obras do autor, efetuou-se uma revisão da literatura acerca dessa temática. Constatou-se que, na concepção frankliana, a dimensão espiritual ou noológica é o ponto fulcral entre essas duas instâncias, e que a própria vida de Frankl é uma referência para se compreender a resiliência enquanto "força desafiadora do espírito".
\end{abstract}

Palavras-chave: Resiliência. Sentido. Espiritualidade.

Abstract: This article aims to identify the relevance and implications of spirituality and resilience in the thought of Viktor Frankl. Therefore, based on the author's principal works, a literature review was conducted about this theme. It was found that in the Franklian conception, the spiritual or noological dimension is the focal point between these two instances and that Frankl's own life is a reference for understanding resilience as a "human spirit's resistance."

Keywords: Resilience. Meaning. Spirituality.

\section{Introduçáo}

O conceito de resiliência deriva da física e foi constituído para designar uma característica de certos corpos que retornam à sua forma original após seres submetidos a uma intensa pressão. Essa mesma concepção se aplica também às ciências humanas, no sentido de resistir determinadas pressóes psicossociais. Moraes \& Rabinovich (1996) destacam a posição do psicólogo Urie Broffenbrenner, que relacionou o conceito de resiliência no contexto de sobreviventes dos campos de concentração que conseguiram superar o trauma daquele período.

Nessa perspectiva encontra-se Viktor Frankl, que foi um psiquiatra sobrevivente de quatro campos de concentração nazistas durante a II Guerra Mundial. Sua narrativa, conforme descreve no livro Em busca de sentido: um psicólogo no campo de concentração (2016a), demonstra a forma pela qual determinados prisioneiros conseguiram suportar

* Doutoranda em Ciências das Religióes (UFPB, João Pessoa-PB)). Bolsista CAPES. Integrante do LAPLAE. ORCID: 0000-0001-5615-033X - contato: josileneufpb@gmail.com

** Professor do Departamento de Ciências das Religiôes da UPFB (João Pessoa-PB). Doutor em Psicologia Social (UFPB). ORCID: 0000-0002-3903-8378 - contato: logosvitae@hotmail.com 
tantos sofrimentos, dores e mortes. No caso do autor em questáo, sua superação decorreu da constituição de sua própria obra, pois encontrou sentido na sua existência ao ajudar outras pessoas a descobrirem um sentido para suas vidas (Frankl, 2011a).

Para Frankl, o sentido na vida foi uma condição necessária para a sobrevivência do prisioneiro; entretanto, não foi suficiente, posto que milhares padeceram nas câmaras de gás. Os prisioneiros que tinham uma razáo para viver conseguiam suportar mais o sofrimento e, por conseguinte, sobreviver ao Shoá (holocausto judeu durante a Segunda Guerra Mundial) quando comparados aos prisioneiros que perdiam a esperança no futuro. Foi nessa condição existencial que Frankl (2016a) vivenciou as palavras de Nietzsche (2017, p. 10): "Quem tem um porquê, enfrenta qualquer como". Após a guerra, Frankl continuou a desenvolver sua teoria, denominada de Logoterapia e Análise Existencial.

A Logoterapia advoga a relevância da consciência de um sentido na vida para a saúde mental, compreendendo a vontade de sentido como a motivaçáo primária do ser humano (Frankl, 2016a). De forma geral, a Logoterapia se constitui a partir de três pilares: liberdade da vontade, vontade de sentido e sentido da vida (Frankl, 2011a). Mas, como se relacionam os conceitos de resiliência e espiritualidade no pensamento frankliano?

Para responder essa pergunta, o presente artigo objetivou identificar a relevância e as implicações dos elementos espiritualidade e resiliência no pensamento de Viktor Frankl. Para tanto, tendo por base as principais obras do autor, efetuou-se uma revisão da literatura, na qual se destacou sua percepção acerca desses elementos e suas interlocuçóes. Dessa forma, o fio condutor deste texto se constituiu em três partes. Inicialmente, apresenta-se as concepçóes relacionadas ao constructo espiritualidade, para, em seguida, apontar as conceituaçóes acerca da resiliência e, por fim, destaca-se a visão frankliana em relaçáo aos constructos destacados neste artigo.

\section{Espiritualidade como dimensão constitutiva do ser humano}

A relevância da espiritualidade nos dias atuais tem sido percebida em funçáo dos diversos estudos realizados "extrapolando a fronteira da teologia e exigindo outras perspectivas para melhor compreensão desse fenômeno humano" (Giovanetti, 2008, p. 129). É preciso lembrar também que "a vida espiritual não é patrimônio das pessoas religiosas" (Torralba, 2013, p. 49) e que, por isso, é necessário contemplar este tema que faz parte da vida de todo ser humano, independente se ele o reconhece ou não. Segundo Frankl (2011a; 2016a), é nessa dimensáo que se encontram as especificidades humanas.

A espiritualidade condensa os questionamentos mais profundos sobre o sentido da existência humana e suas açôes no mundo. No dizer poético de Teixeira (2008, p. 30), a "espiritualidade náo é nada mais do que esse fabuloso convite para nos banharmos nas águas desse lugar além das palavras e é a cristalina fonte de todo o sentido".

A espiritualidade, nessas perspectivas, está vinculada à transcendência, ou seja, para algo (interesses práticos e criativos) ou alguém (um ser amado ou um Deus pessoal) além de si mesmo. 
A vida espiritual refere-se a algo transcendente que, no entanto, não é necessariamente divino. Nesse sentido, implica um certo grau de exercício consciente da liberdade. A espiritualidade é uma ruptura desejada do dado, uma ruptura da cerca da imanência autossuficiente. A experiência espiritual é articulada como um movimento para o plano superior da realidade através de sua busca, mas também através da aceitação como um dom gratuito. (Torralba, 2019, p. 105, tradução nossa)

Nesse seguimento, o autor supracitado lembra ainda que "a sensibilidade espiritual, ou espiritualidade, é, essencialmente, uma transformação da pessoa que exige um trabalho sobre si mesmo, um trabalho sobre o próprio eu" (Torralba, 2013, p. 40). Dessa forma, encontra-se a relevância antropológica que tem a temática da espiritualidade, e esse, talvez, seja um dos motivos da mesma ter ultrapassado seu campo originário de abordagem que, em suas origens, remetia à teologia e/ou filosofia. Atualmente, o tema da espiritualidade tem sido objeto de diversos estudos, tendo em vista a sua necessidade de maior compreensão (Giovanetti, 2008).

A espiritualidade, em sua acepção mais simples, pode ser compreendida como uma atividade típica do espírito humano, mas que náo precisa ser atrelada ou vinculada a uma perspectiva de fé, pois “o termo 'espiritualidade' designa toda vivência que pode produzir mudança profunda no interior do homem e o leva à integração pessoal e à integração com outros homens" (Giovanetti, 2008, p. 137). Desse modo, ela pode ser vista como um elo de integração entre os seres humanos, sendo aquilo que se tem em comum e norteia suas ações enquanto espécie humana.

Além dessa integração sugerida por Giovanetti (2008), outros elementos fazem parte dessa dimensão, a exemplo das questóes existenciais. O ser humano pode ser compreendido como um ser em busca de sentido, visto que vive numa inquietação incessante, pois:

O anseio por uma vida plena, a aspiração à total realização, são características perfeitamente identificáveis no ser humano. Elas se expressam de múltiplas maneiras, porém, em sua experiência de ser inacabado, o ser humano está sempre em busca de algo (Torralba, 2013, p. 67).

O cultivo da dimensão espiritual possibilita a descoberta de que "a vida não é um fechamento em si mesmo, mas uma abertura para o outro" (Giovanetti, 2008, p. 139). Nessa perspectiva, encontra-se a indicação de Teixeira (2008) evidenciando que o cultivo da espiritualidade pode proporcionar a humildade e a humanização no processo de aproximação e engajamento com os mais pobres, e desse modo, a "experiência da gratuidade do amor a Deus e o cultivo da espiritualidade tornam-se essenciais no processo de aproximaçáo e encontro pleno com os outros, conferindo-lhe verdadeira significação" (Teixeira, 2008, p. 29).

Dessa forma, neste artigo, destaca-se essa perspectiva de uma espiritualidade compreendida como abertura para o mundo. Não há possibilidade de compreensão de uma espiritualidade retraída, fechada, isolada, ou seja, o ser humano, enquanto ser espiritualmente desenvolvido, só pode ser compreendido nas suas relaçóes com o mundo e consigo mesmo. Ainda que, para alguns, esse movimento de abertura seja difícil ou permeado de obstáculos, até porque nem todos estáo dispostos a dialogar com o outro, com o diferente. 
O desenvolver-se na esfera espiritual apresenta uma riqueza, porque, a partir desse desenvolvimento, é possível a saída de si para adentrar no mundo do outro sem imposiçóes - só a espiritualidade "permite o fluir, permite que a pessoa se desprenda de si mesma e se entregue. A vida espiritual não é fechamento, intransigência, menos ainda autismo. É, bem ao contrário, fluidez, doação e abertura" (Torralba, 2013, p. 47). O autor também destaca que "a pessoa espiritualmente inteligente vive todas as suas relações, sensações, conhecimentos e experiências a partir do espiritual, que engloba a totalidade da vida humana" (Torralba, 2013, p. 50). Nessa direção, Chequini (2007) evidencia que essa dinâmica interior promove uma relaçáo harmônica com o exterior, pois

A espiritualidade é entendida pela maioria dos estudiosos como característica intrínseca
do ser humano, que busca sentido e significado para a existência e considera fatores
como o nível de conhecimento pessoal, o reconhecimento de uma verdade universal
ou de poder superior capaz de nos remeter a uma sensaçáo de plenitude e bem-estar
com o mundo, de unidade com o cosmos e com a natureza (Chequini, 2007, p. 95).

De acordo com o que indica Torralba (2013, pp. 44-45), "a vida espiritual não é uma vida paralela à vida corporal. Está intimamente unida a ela.” Nessa perspectiva, compreende-se que essa vivência espiritual não se coloca num plano diferente do humano - ainda que o lugar reservado a ela se compreenda num plano mais elevado na teoria frankliana, ela permanece integrada ao ser humano com suas dimensóes e, por isso, é preciso relembrar que "seguindo o pensamento de Viktor Frankl, consideramos o espiritual como o que é livre no ser humano, como aquilo que escapa ao biológico, embora esteja intrinsecamente unido ao somático" (Torralba, 2013, pp. 44-45). O próprio Frankl afirma:

Das realidades existenciais do homem participam: a espiritualidade, a liberdade e a responsabilidade. Essas três realidades existenciais náo caracterizam apenas a existência humana como tal, como humana; a bem dizer, elas a constituem. Nesse sentido, a espiritualidade do homem não é só um caracteristicum, mas sim um constituens: o espiritual não é algo que só caracteriza o homem, a exemplo do corporal e do psíquico, que são próprios também do animal; o espiritual é algo que distingue o homem, que é privativo só dele e antes de tudo dele. (Frankl, 1995, p. 75)

Conforme a assertiva anterior do autor, fica claro que a espiritualidade não é só uma dentre as dimensões, mas, para Frankl, ela é a dimensão mais ampla, pois abarca o psicofísico. Logo, é necessário lembrar que "não somos seres unidimensionais, mas multifacetários, e a multiplicidade de inteligências que subsiste em cada um de nós permite darmos respostas a situaçóes muito diferentes" (Torralba, 2013, p. 22). Completando essa argumentação, Lukas (1989, p. 28) afirma que na "dimensão espiritual localiza-se a tomada de posição, livre, em face das condiçóes corporais e de existência psíquica”.

Nessa perspectiva, "as decisóes pessoais da vontade, intencionalidade, interesse prático e artístico, pensamento criativo, religiosidade, senso ético ('consciência moral') e compreensão do valor” (Lukas, 1989, pp. 28-29), estão no interior dessa dimensão, fazendo com que a mesma seja táo relevante para cada pessoa, ainda que ela (a pessoa) não tenha consciência dessa relevância. Para se compreender melhor essa afirmação, neste manuscrito, apresenta-se no item que segue, uma síntese do histórico desse constructo 
enfatizando também as diversas conceituações desde sua origem etimológica até interpretaçóes diversas e atuais acerca da resiliência.

\title{
Resiliência: a força desafiadora do espírito
}

O conceito de resiliência foi recentemente introduzido nas ciências sociais e na medicina, vindo, como é bem conhecido, do campo da engenharia. Acevedo e Battafarano (2008) indicam as origens do uso do termo no campo das ciências exatas; posteriormente, foi introduzido no campo das ciências humanas. Conforme também indica Brandão et al (2011), inclusive, fazendo referência à sua inserção no contexto da psicologia associada aos estudos da vulnerabilidade.

De acordo com Brandão et al (2011), entre as décadas de 1970 e 1980, alguns pesquisadores norte-americanos e ingleses começaram a dar atenção "para o fenômeno das pessoas que permaneciam saudáveis apesar de expostas a severas adversidades. Chamaram inicialmente essas pessoas de invulneráveis e, o fenômeno, de invulnerabilidade, como o termo que seria mais tarde substituído por resiliência" (Brandão et al, 2011, p. 263).

Etimologicamente, o vocábulo se origina do latim resiliens que "significa saltar, voltar, ser impelido, recuar, encolher-se, romper" (Fajardo; Minayo \& Moreira, 2010, p. 762). Os referidos autores também lembram que os diversos conceitos atribuídos ao termo variam de acordo com o objeto, com o material e também com os seres vivos. Eles destacam:

\begin{abstract}
[...] existem no dicionário de língua inglesa dois raciocínios para o termo resiliência que se aplicam tanto para materiais quanto a pessoas. $O$ primeiro se refere à habilidade de voltar rapidamente para seu estado normal de saúde ou de espírito depois de passar por doenças e dificuldades, por exemplo. A segunda acepçáo diz respeito à propriedade de uma substância retornar à sua forma original quando a pressão é removida. Esta última remete ao conceito original atribuído à Engenharia e à Física que busca estudar até que ponto um material sofre impacto, volta ao seu estado original e não fica deformado quando tais forças deixam de atuar sobre o mesmo (Fajardo; Minayo \& Moreira, 2010, p. 764).
\end{abstract}

Diversos autores concordam com essas considerações acerca do termo resiliência e de suas origens vinculadas ao âmbito da engenharia e da física, porém, o mais significativo se encontra na sua relação ou ligação com a capacidade/habilidade humana que pode ser um fator de reabilitação da saúde. É preciso lembrar que "ao falar em resiliência humana, afirma-se que é a capacidade de uma pessoa ou de um sistema social viver de maneira saudável e se desenvolver humanamente, apesar das difíceis condições da vida e ainda mais, emergir fortalecido e renovado por elas" (Acevedo; Battafarano, 2008, p. 66, tradução nossa). Vale lembrar que a resiliência é vista como um dos fenômenos que se compreende como constitutivo do ser humano.

O que é indicado hoje com o conceito de "resiliência" ou, até, "crescimento pós-traumático" - como a capacidade de manter um equilíbrio psicológico estável, mesmo em situaçóes de luto, sofrimento e trauma ou, ainda, para torná-las uma oportunidade de crescimento - já havia sido indicado por Frankl, com o nome de "força espiritual", como uma competência tipicamente humana, enraizada no nível espiritual da pessoa e expressa desempenho suportado por valores de atitude (Bellantoni, 2019, pp. 64-65, tradução nossa). 
Ao compartilhar esse pensamento, apresenta-se a resiliência como uma competência/ habilidade humana enraizada na dimensão espiritual. Para Torralba (2013), acrescenta-se a essa integração resiliência/dimensão espiritual a liberdade, tendo em vista que "ser livre é, entre outras coisas, pensar por si mesmo, realizar as decisóes oportunas conforme a própria visão do mundo e dos valores, tomar as rédeas da própria vida e assumir a própria identidade" (Torralba, 2013, p. 270).

É preciso enfatizar, além disso, que a resiliência é formada ou desenvolvida a partir de um conjunto de fatores que incluem questóes biológicas na mesma medida em que se inserem questóes sociais, como indica o psicanalista francês Boris Cyrulnik (2006):

É melhor dizer que a resiliência é um processo diacrônico e sincrônico: as forças biológicas do desenvolvimento sáo articuladas com o contexto social para criar uma representação do eu que permite a historização do sujeito. Pode-se dizer, mais simplesmente, que a resiliência é um tecido que dá um nó na lá do desenvolvimento aumentado com uma lã afetiva e social. Portanto, é melhor descrever um itinerário de personalidade resiliente e tentar entender como ele se infiltra nos golpes do destino, mas se tecer com apoios sólidos. (Cyrulnik, 2006, p. 40)

Dito de outro modo, a resiliência integra as forças que o ser humano possui biologicamente e o contexto social em que este se encontra inserido, formando uma só teia que se torna mais resistente aos abalos e "golpes do destino", pois os fios, em separado, são muito mais sensíveis e passíveis de ruptura do que integrados, como sugere o autor ao tratar dos sujeitos resilientes. Boris Cyrulnik, "visualiza resiliência como um oxímoron, em que o sujeito é cindido por um trauma, mas se reconstrói e resiste; sofre, mas tem esperança apesar de tudo" (Silveira; Mahfoud, 2008, p. 569). De acordo com os autores, essa concepçáo de Cyrulnik (2006) coloca a resiliência numa articulaçáo de duas interfaces, a princípio distintas: o individual e o coletivo, porque ela integra a intimidade do indivíduo e um processo social.

Essa integração sugerida por Cyrulnik (2006) justifica sua tese de que a resiliência seria um oxímoro, já que consiste em reunir dois termos antinômicos; seria uma espécie de "alquimia da dor", como indica García (2011), tendo em vista que, baseando-se em Cyrulnik, ele argumenta que a resiliência ocorre "quando um evento doloroso adquire valor e se torna um marco para visualizar a direção de nossa vida, ele adquire significado para nós e para de doer" (García, 2011, p. 170). Nessa mesma perspectiva, Silveira e Mahfoud (2008, p. 569) ressaltam que a resiliência pode ser vista "como a capacidade de transformar uma situação de dor em possibilidade de crescimento".

A resiliência pode ser compreendida como a capacidade de enfrentar o sofrimento, "reconstruir a si mesmo e não perder a capacidade de amar, lutar, resistir, buscar não é uma habilidade que deva ser dominada, mas uma realidade que deve ser descoberta, que deve ser empregada. É mais do que resistir, é aprender a viver, é buscar significado" (Acevedo; Battafarano, 2008, p. 67, tradução nossa).

De acordo com os autores acima citados, a resiliência constitui-se de um potencial dinâmico e saudável - pode-se acrescentar que é nesse potencial que é possível encontrar os impulsos necessários para a restauração da saúde, seja ela na dimensão física ou psíquica. Ser resiliente significa atuar com consciência sobre o sofrimento vivenciado, seja uma doença, uma perda, uma situação de luto, entre outros, fazendo com que este 
mal se transforme em um bem, que essa dor se torne uma mola propulsora de sentimentos positivos como coragem, alegria, prazer, humor, etc. É preciso compreender que esse bem, em geral, condensa-se nos benefícios presentes na saúde, mas que, na concepção logoterapêutica, poder-se-ia dizer que são benefícios que atuam diretamente na dimensão espiritual, tendo em vista que é nela que se origina a resiliência.

Assim, o ser humano é sempre um ser que decide qual atitude tomar, mesmo diante de situaçóes desafiadoras ou de sofrimento, como ocorre muitas vezes nos momentos em que precisa demonstrar força, daí uma possível associação à nomenclatura atribuída por Frankl de "força desafiadora do espírito" (Freitas, 2017, p. 144).

Alguns autores, a exemplo de Lima (2010), defendem que a própria vida de Frankl poderia ser vista como um modelo de resiliência. Nessa perspectiva, destaca-se que "Viktor Frankl, não só sobreviveu ao campo de concentração, como também soube dar 'sentido' ao seu sofrimento, transformando-se e crescendo com a dor” (Lima, 2010, p. 1). Embora Frankl não tenha citado diretamente o termo, percebe-se em seus manuscritos um efetivo contributo ao conceito de resiliência quando discorre acerca da dimensão espiritual/noológica. Essa perspectiva será discorrida no tópico a seguir.

\section{A visão frankliana acerca da espiritualidade e da resiliência}

A espiritualidade auxilia na compreensão das contingências e limitaçóes humanas, tendo em vista que o "espírito nos permite fazer a experiência da profundidade, da captação do simbólico, de mostrar que o que move a vida é um sentido, pois só o espírito é capaz de descobrir um sentido para existência" (Giovanetti, 2008, p. 138). Nesse ponto, torna-se necessário lembrar que não se trata de uma busca para além do humano e, por isso, a espiritualidade não necessariamente conduz o ser humano a uma conexão com um ser transcendente, até porque, continua o autor: "a espiritualidade pertence a todo homem, embora ela não seja cultivada por todo homem. Ela é própria do homem, mas nem todos fazem dela o direcionador de suas vidas" (Giovanetti, 2008, pp. 138-139). Este sentido é enfatizado nas palavras de Torralba (2013):

A vida espiritual não é patrimônio das pessoas religiosas. Todo ser humano, pelo simples fato de existir, é capaz de vida espiritual, de cultivá-la dentro e fora do âmbito das religióes. Em virtude de sua inteligência espiritual, tem necessidade de dar sentido à sua existência e ao mundo em que vive, experimenta sua existência como problemática e necessita pensar o que deve fazer com ela. (Torralba, 2013, p. 49)

Nessa exposição, percebe-se que a essência da espiritualidade se situa para além da perspectiva religiosa; ela é, antes de qualquer outra coisa, um dado antropológico - faz parte da própria constituição do ser humano. Dessa forma, todo e qualquer ser humano possui espiritualidade, ainda que não seja religioso.

Em última análise, pode-se dizer que na dimensão espiritual encontram-se as sensaçóes e indagaçóes mais profundas da existência humana, que, ao mesmo tempo, são as mais elevadas. $\mathrm{O}$ ser humano se coloca numa condição de um ser livre para resolver como se posicionar diante de determinadas situações e usar sua liberdade "que emana da potência espiritual de seu ser, permite-lhe dispor de sua própria força, utilizar a que 
traz consigo, presente no sentimento de disposiçáo e no impulso à atividade, tanto para a atividade corporal quanto para a intelectual" (Torralba, 2013, p. 63). Dessa forma, "a espiritualidade é inerente ao ser humano enquanto tal. É válido dizer que ninguém é psicologicamente adulto sem que seja 'espiritual'” (Valle, 2008, p. 102). Ademais, destaca-se ainda outro elemento significativo quanto à espiritualidade, a saber, a sua contribuição para a busca de sentido, ou, em outros termos, àquilo que contribui diretamente para a descoberta do sentido da vida.

A expressão "sentido da vida" inclui, ao menos, três significados: em primeiro lugar, refere-se ao significado que contém os múltiplos acontecimentos que configuram a vida. Isso supõe que a vida humana, com todas as suas ondulaçóes, possui uma lógica. O segundo significado se apoia na imagem da direção, como a do curso de um rio. Tal imagem representa a vida como uma sucessáo de momentos orientados entre um antes e um depois, uma espera e um cumprimento, uma possibilidade e uma realização. É a qualidade que faz da mera sucessão de fatos uma história formada por acontecimentos que se iluminam uns aos outros e se orientam de acordo com um princípio e um fim. O terceiro significado leva à relação entre sentido e valor e, aplicado à vida, é o que a torna digna de apreço e o que justifica que valha a pena ser vivida (Torralba, 2013, pp. 69-70).

O autor acrescenta que "a existência do ser humano é aberta para o interior, é uma existência aberta para si mesma, mas também aberta para fora” (Torralba, 2013, p. 105), e isto se torna possível porque, como ser constituído espiritualmente, "faz parte da essência do homem seu ser orientado para, seja para alguma coisa, seja para alguém, seja para uma obra, seja para um homem, para uma ideia ou para uma pessoa!" (Frankl, 1995, p. 83). Dito de outro modo, o ser humano só realmente compreende o sentido de sua existência quando volta seu olhar para algo além de si mesmo, seja uma pessoa, um projeto, um trabalho a ser desenvolvido, entre outras coisas - o que foi denominado de autotranscendência.

Desse modo, torna-se compreensível a defesa da tese de que a espiritualidade é a mola propulsora dessa realização de sentido da vida como uma instância que contempla as buscas mais profundas do ser humano. Essas instâncias estão intimamente relacionadas, tendo em vista que não se tem conhecimento de um indivíduo que tenha passado pela experiência de viver de forma isolada realizando-se consigo mesmo. E isso se deve à dimensão espiritual pelo fato de ser nela onde se encontram as especificidades humanas. Acrescenta Frankl: "'ex-sistir' quer dizer sair de si mesmo e colocar-se diante de si mesmo, de sorte que o homem sai do nível da corporalidade psíquica e chega a si mesmo passando pelo âmbito do espiritual. A existência acontece no espírito" (Frankl, 1995, p. 63), o que significa um movimento de autodistanciamento.

$\mathrm{O}$ autodistanciamento consiste na capacidade humana de "distanciar-se náo apenas de uma situação, mas de si mesmo" (Frankl, 2011a, p. 27). Trata-se, pois, de uma característica antropológica que, na mesma medida que a autotranscendência, pode ser visto como elemento constitutivo de toda e qualquer pessoa. A partir do autodistanciamento, o ser humano "é capaz de escolher uma atitude com respeito a si mesmo e, assim fazendo, consegue tomar posição, colocar-se diante de seus condicionamentos psíquicos e biológicos" (Frankl, 2011a, p. 27). 
Retornando à questão do sentido da vida, de acordo com o mentor da logoterapia, o sentido pode ser encontrado por três vias:

\begin{abstract}
Vamos resumir. A vida pode assumir significado de três maneiras: primeiro, pelo que damos à vida (em termos de obras criativas); segundo, pelo que tiramos do mundo (em termos de nossa experiência de valores); e terceiro, pela abordagem que fazemos a um destino que não podemos mais mudar (uma doença incurável, um câncer inoperável ou coisas assim). No entanto, mesmo à parte isso, o homem não pode evitar enfrentar sua condição humana, que inclui o que chamo de trágica tríade da existência humana, a saber: dor, morte e culpa. Por dor quero dizer sofrimento; pelos outros dois constituintes da tríade trágica, entendo a dupla faceta da mortalidade e da falibilidade humana (Frankl, 2011b, p. 30).
\end{abstract}

Essas três vias - denominadas por Frankl (2011a) como valores criativos, valores vivenciais e valores atitudinais - direcionam o ser humano para o encontro e realização de sentido, cada qual a seu modo e não sendo excludentes, mas complementares. Eles indicam caminhos que podem ser percorridos pelo ser humano para a concretização de uma vida plena. Esse percurso pode ser compreendido como um processo que pode ser desenvolvido de diversos modos, dentre eles, o educar espiritualmente.

No entanto, é preciso frisar que Frankl (2011a), não sugere a fuga ao sofrimento. Ele vê no seu enfrentamento a possibilidade de desenvolvimento da resiliência, denominada por Frankl como "a força desafiadora do espírito", conforme sugere Freitas:

\begin{abstract}
Para Frankl, é a "força desafiadora do espírito" que permite o antagonismo noopsíquico nas situaçóes de adversidades, perante as quais a pessoa deve se sobrepor aos condicionamentos psicofísicos e sociais. Ou seja, a resiliência se manifesta no corpo e nas emoções, mas se origina na dimensão noética, a propriamente humana. A atitude resiliente é um grande fator protetor da saúde física e mental, evidenciando principalmente naquelas pessoas que sofreram estresse precoce (Freitas, 2017, p. 144).
\end{abstract}

Nessa perspectiva, percebe-se a integração existente entre a resiliência e as demais dimensóes do ser humano, demonstrando, assim, que seu desenvolvimento pode e deve contribuir para a manutenção da saúde física e mental. Lembrando que as concepções de saúde e doença precisam ser vistas como duas perspectivas presentes na existência humana, e por mais que se queira evitar as doenças, elas estáo presentes como num processo de complementaridade com a saúde, ou seja, só se tem ideia de que se está doente quando não se está saudável. Nessa direção, de acordo com a afirmação de Acevedo e Battafarano (2008), esses dois estágios - saúde e doença - constituem-se nos dois extremos opostos na dinâmica existencial. Nessa perspectiva, "a resiliência [oferece] um potencial dinâmico e saudável que se manifesta nas diferentes dimensôes humanas pela possibilidade de viver respondendo a necessidades biológicas, psicológicas e existenciais" (Acevedo; Battafarano, 2008, p. 45, tradução nossa).

A resiliência pode ser definida como "a capacidade humana para enfrentar, vencer e ser fortalecido ou transformado por experiências de adversidade" (Melillo; Ojeda, 2005, p. 15). De forma geral, é compreendida como capacidade de enfrentamento de situaçóes adversas e erguer-se com mais vigor a partir das mesmas. Pode-se dizer que "é um potencial do espírito humano que pode ser atualizado em circunstâncias que ataquem a integridade pessoal ou comunitária, sejam estas situaçóes previsíveis ou mesmo inesperadas" (Acevedo; Battafarano, 2008, p. 16, tradução nossa); os 
autores supracitados acrescentam que Viktor Frankl falou sobre esta capacidade sem nomeá-la.

É na aproximação existente entre dimensão espiritual e resiliência que se sustenta a presente exposição, uma vez que

A partir da logoterapia pode-se entender o conceito de resiliência como a capacidade do ser humano náo se sujeitar exclusivamente às circunstâncias, poder-se-ia dizer: ele é filho de seu passado, mas não escravo de seu passado, ele é o pai de seu futuro (Acevedo; Battafarano, 2008, p. 69, tradução nossa).

Desse modo, é possível inferir que a resiliência é um potencial que todos os seres humanos possuem e podem desenvolver, uns mais, outros menos, mas que não existe a possibilidade de ausência; assim como a espiritualidade, ela está lá, latente, podendo ser desenvolvida ou ampliada em qualquer período da vida, até porque o espiritual, assim como a resiliência, pode ser visto como um "potencial, está ali, portanto, pode ser atualizado ou náo. A resiliência pode, portanto, ser apresentada em qualquer momento da vida, não se limitando exclusivamente à infância" (Acevedo; Battafarano, 2008, p. 23, tradução nossa).

Assim, pode-se vislumbrar a resiliência como um potencial espiritual que pode variar de pessoa para pessoa, mas que, inevitavelmente, todos trazem consigo, e que as condiçóes diversas que perpassam a existência humana podem contribuir ou náo para seu desenvolvimento. Nessa direção, Freitas (2018) lembra que

\footnotetext{
Esse "poder de resistência do espírito" ou "força desafiadora do espírito" é decorrente da noodinâmica, do movimento interno que nos faz sair de uma posição de conforto a seguir, atraídos por um sentido a realizar, por um valor a ser concretizado. [...] Toda pessoa tem esse poder em potencial, que pode e deve ser desenvolvido. Toda pessoa é mais forte do que pensa; ninguém tem o direito de menosprezar a própria fortaleza, sua riqueza interior e suas potencialidades (Freitas, 2018, pp. 60-61).
}

Retomando as palavras de Freitas (2018), encontra-se na resiliência um "poder potencial" uma "riqueza interior" que precisa ser, impreterivelmente, descoberta e desenvolvida, pois, de acordo com Frankl (2016a, p. 91), "sempre e em toda parte, a pessoa está colocada diante da decisão de transformar a sua situação de mero sofrimento numa realização interior de valores", o que pode ser compreendido como uma autêntica atitude resiliente, pois, em geral, as situaçôes de sofrimento transformam-se em oportunidades de realização e/ou crescimento pessoal. A partir das consideraçóes discorridas, pode-se inferir que o desenvolvimento da resiliência é umas das mais importantes responsabilidades que a sociedade precisa assumir em sua existência, tendo em vista seu potencial libertador.

Silveira e Mahfoud (2008, p. 570) destacam que "a logoteoria afirma a 'autonomia da existência espiritual' e disso decorre o 'senso de responsabilidade'. O ser humano é, em essência, ser-responsável [...] e a responsabilidade está na ação no momento presente ('aqui e agora')". Desse modo, o ser humano só pode ser visto em sua totalidade quando atua responsavelmente no "aqui e agora", pois, para Frankl (2016b), o ser humano é o ser que decide responsavelmente: "o ser responsável, ou ter responsabilidade, é a base fundamental da pessoa enquanto ser espiritual, não meramente impulsivo" (Frankl, 
2016b, p. 17). Desse modo, considera-se que também seja responsabilidade do ser humano investir no desenvolvimento desse potencial espiritual mediante a resiliência.

Além disso, diversos autores, como será exposto a seguir, demonstram a relevância social da resiliência: ainda que seja caracterizada como um fenômeno que se desenvolve na individualidade, ela traz benefícios ao convívio em sociedade, como indicam os autores a seguir:
A resiliência não pode e não deve ser vista apenas como um meio adaptativo, com um critério de homeostase e sobrevivência individual ou de grupo, é uma resposta a situaçóes externas, é a capacidade do ser humano de permanecer integrado apesar da adversidade e buscar o desenvolvimento com um senso de concordância com sua consciência e com os objetivos de sua própria cultura e/ou como ator social em relação aos outros (Acevedo; Battafarano, 2008, p. 45, tradução nossa).

Enfatiza-se o papel social da resiliência, que, além de contribuir com o desenvolvimento do indivíduo, fazendo com que esse possa sair mais forte de situaçóes ditas adversas, o indivíduo aprende a lidar melhor com o universo externo; ele fortalece seu interior e enfrenta o exterior.

Nessa direçáo, Acevedo e Girons (2018, p. 40) destacam que "ao falar de resiliência humana, afirma-se que é a capacidade de uma pessoa ou de um sistema social para viver de forma saudável e desenvolver-se humanamente, apesar das difíceis condiçóes de vida e, para sair fortalecidos e ser renovados por elas". Nessa exposição dos autores, destacam-se duas afirmaçôes: 1) desenvolver-se humanamente e 2) sair fortalecido e renovado. Essas colocaçôes demonstram mais uma vez a relevância social de desenvolver a resiliência, porque as pessoas ditas resilientes podem ser vistas como pessoas mais sensíveis e humanas, facilitando, assim, o processo de empatia, o que pode auxiliar nas relaçóes interpessoais, inclusive em ambientes de trabalho; e, ainda, como pessoas mais suscetíveis a aceitar mudanças, já que o processo de renovação que pode ser possibilitado pela resiliência também pode contribuir para essa aceitação.

Ainda sobre sua relevância social, destacam-se as palavras de Acevedo e Battafarano (2008), os quais elencam quatro pontos nos quais a resiliência pode ajudar no convívio social:
A resiliência nos ajuda a nos distanciarmos:
de desânimo, como realismo sem esperança
de cinismo, incapaz de ver a face positiva da realidade
de ilusôes irreais
da tirania do determinismo (Acevedo; Battafarano, 2008, p. 75, traduçáo nossa).

Cada um desses elementos: desânimo, cinismo, ilusóes e tirania do determinismo, podem se constituir como barreiras nas relaçóes sociais, porém, como sugerem os autores, a resiliência protege e distancia as pessoas destas instâncias, visto que, enquanto fortalece interiormente, ela auxilia no combate destes elementos. Essa "força de resistência do espírito" nas palavras de Bruzzone (2011) é o que capacita cada pessoa para a tomada de decisão de seu próprio destino, considerando que ela fortalece o ser humano na luta contra as influências do meio ambiente.

Portanto, é preciso valorizar a resiliência enquanto fenômeno humano, que tem muito a contribuir com o processo de "reumanização". Desse modo, é necessário cada 
vez mais estimular o desenvolvimento da mesma, tanto porque ela tem muito a contribuir em diversas esferas - inclusive na social, como já foi destacado - como pelo fato de se constituir como uma instância que integra a dimensão espiritual. Além disso, "a percepção e a realização do sentido da existência implicam a atualização das possibilidades dentro das condições que impóem certas situaçôes da vida. Ao 'ser-sendo para chegar a ser', somos resilientes, pois nos mobilizamos para o sentido sobrepondo-nos à dificuldade" (Acevedo \& Girons, 2018, p. 40).

Ademais, para Frankl, a dimensão espiritual denominada de noológica é vista como aquela que condensa todas as outras dimensóes e pode proporcionar a soluçáo das projeçōes ambíguas e controversas geradas nos planos mais baixos. Segundo ele, a dimensão noológica ou espiritual é, para o ser humano, "não a única, mas sim a específica, de sua existência, quer se considere o espiritual no homem de maneira fenomenológica, como sua personalidade, quer de maneira antropológica, como sua existencialidade" (Frankl, 1995, p. 66).

$\mathrm{O}$ autor destaca que os condicionamentos biológicos e psicológicos podem e devem ser superados pela atitude que o ser humano tem perante dada circunstância. Desse modo, o "que importa, logo, não são os condicionantes psicológicos ou os instintos por si mesmos, mas, sim, a atitude que tomamos diante deles. É a capacidade de posicionar-se dessa maneira que faz de nós seres humanos" (Frankl, 2011a, p. 27).

É preciso enfatizar ainda que essa estrutura dimensional que condensa a totalidade do ser humano, proposta por Frankl, consiste num constructo que enfatiza as especificidades humanas contidas na dimensão noética ou noológica e suas capacidades de desdobramentos pautadas nos princípios da liberdade e responsabilidade. Para Frankl (2011a, p. 66) "a liberdade pode corromper-se em mera arbitrariedade, a menos que seja vivida nos termos de uma responsabilidade". Pode-se compreender esses princípios, na visão frankliana, como aqueles que servem de ponto de equilíbrio para as atitudes humanas.

Na concepçáo frankliana, a dimensão noética é aquela mais elevada e que contempla a essência do ser humano. Essa concepçáo do autor pode ter surgido em função de sua experiência nos campos de concentraçáo, período que o fez afirmar que "a liberdade espiritual do ser humano, a qual não se lhe pode tirar, permite-lhe, até o último suspiro, configurar sua vida de modo que tenha sentido" (Frankl, 2016a, p. 89). Em última instância, ele defende uma liberdade diferente: "a do espírito", ou seja, aquela que se encontra num nível diferenciado, mais alto.

É a partir da inclusão da dimensão espiritual, uma das contribuiçóes mais importantes de Viktor Frankl para a compreensáo do modo humano de adoecer, e da noçáo de que "O espírito não fica doente" [...] então quando, como seres humanos, como pessoas, não podemos mais falar de doença: há muitas categorias noológicas; na esfera do espírito pessoal, as categorias noológicas governam; mas estes não se referem ao plano do 'saudável doente', mas do 'verdadeiro-falso'. (Acevedo; Battafarano, 2008, p. 59, tradução nossa)

É importante ressaltar que essa dimensão não se desconecta das demais instâncias do ser humano, ela não ocorre para além da esfera humana; ela é "algo que toca em 
profundidade sua vida e experiência. [...] Daí se poder falar em experiência espiritual enquanto movimento e busca do sentido radical que habita a realidade" (Teixeira, 2008, p. 15). Dito de outro modo, não é possível falar em dimensão espiritual ou noológica (em termos franklianos) sem que se trate da experiência humana.

Além disso, o mentor da logoterapia relembra que a dimensão espiritual é uma das demais dimensões que integram o ser humano em sua totalidade, pois ela "não é apenas uma dimensão própria do homem; ela é a dimensão específica dele. [...] Não se trata, contudo, no que diz respeito a ela, da única dimensão dele, dado que o ser humano é uma unidade e um todo corporal, psíquico e espiritual" (Frankl, 1995, p. 66). Destarte, Frankl (1995) combate as perspectivas reducionistas que consideram, em muitos casos, apenas uma ou outra dimensão humana, deixando de levar em conta o ser humano em todas as suas instâncias. Com o olhar minucioso, Frankl inclui em sua teoria a abordagem de todas as dimensóes que constituem o ser humano, e, dentre elas, a espiritual.

\section{Consideraçóes finais}

O objetivo deste artigo foi identificar a relevância e as implicaçóes dos constructos espiritualidade e resiliência no pensamento de Viktor Frankl, tendo duas perguntas norteadoras: como se relacionam os conceitos de resiliência e espiritualidade no pensamento frankliano? E onde se entrelaçam as concepçóes de resiliência e de espiritualidade no pensamento frankliano?

A partir das consideraçôes aqui discorridas, pôde-se considerar que a resiliência, na perspectiva da logoterapia, seria um elemento complementar ou integrativo da espiritualidade; que esta última se manifestaria, sobretudo, por meio da autotranscendência e do autodistanciamento, considerando que tais fenômenos humanos têm suas raízes na dimensão espiritual/noológica.

De forma metafórica, Frankl (1978) compreendia que quando as árvores, em uma floresta, não podem se expandir horizontalmente, crescem verticalmente. Para o autor, sofrer significa agir e crescer, o que resulta no processo de maturidade. À medida em que se sofre por algo ou por alguém, pode-se compreender que o processo de resiliência requer a capacidade humana de autotranscendência, pois o sofrimento teria sentido na medida em que se sofre por amor a alguém. Ademais, requer uma atitude ou postura interior, tendo em conta que o "que importa é a audácia, a coragem de sofrer, trata-se de aceitar o sofrimento, dizer "sim" ao destino, enfrentá-lo. Somente por esse caminho nos aproximaremos da verdade, e náo pelos caminhos da fuga e de medo ao sofrimento" (Frankl, 1978, p. 243).

O processo de maturidade e da resiliência requer um refinamento por meio da aceitação do sofrimento inevitável, tendo em conta que sofrimento sem sentido significa desespero, na perspectiva frankliana. Assim, pode-se dizer "sim à vida, apesar de tudo", à medida em que o ser humano encontre um sentido para ser e permanecer resiliente. 


\section{Referências}

ACEVEDO, Geronimo; BATTAFARANO, Mauricio. Conciencia y resiliencia. Buenos Aires: Centro Viktor Frankl para la difusión de la Logoterapia, 2008.

ACEVEDO, Geronimo; GIRONS, Cecilia Saint. O modo humano de adoecer. In: OLIVEROS, Olga Lehmann; KROEFF, Paulo (Orgs.). Finitude e sentido da vida: a logoterapia no embate com a tríade trágica. Vol. 2. Porto Alegre: Evangraf, 2018, pp. $9-42$.

BELLANTONI, Domenico. Religione, spiritulità e senso della vita: La dimensione transcendente come fattore di promozione dell'umano. Milano/Itália: FrancoAngeli, 2019.

BRANDÃO, Juliana Mendanha; MAHFOUD, Miguel; GIANORDOLINASCIMENTO, Ingrid Faria. A construção do conceito de resiliência em psicologia: discutindo as origens. In: Paidéia, 2011, v. 21, n. 49, pp. 263-271.

BRUZZONE, Daniele. Afinar la consciência: Educación y búsqueda de sentido a partir de Viktor E. Frankl. Buenos Aires: San Pablo, 2011.

CHEQUINI, Maria Cecília Menegatti. A relevância da espiritualidade no processo de resiliência. In: Psic. Rev. São Paulo, volume 16, n.1 e n.2, pp. 93-117, 2007.

CYRULNIK, B. La maravilla del dolor: el sentido de la resiliencia. Buenos Aires: Granica, 2006.

FAJARDO, Indinalva N.; MINAYO, Maria Cecília de S.; MOREIRA, Carlos Otávio F. Educação escolar e resiliência: política de educação e a prática docente em meios adversos. In: Ensaio: aval. pol. públ. Educ., Rio de janeiro, v. 18, n. 69, pp. 761-774, out./dez. 2010.

FRANKL, Viktor E. Fundamentos Antropológicos da Psicoterapia. Rio de Janeiro: Zahar Editores, 1978.

FRANKL, Viktor E. Logoterapia e análise existencial: textos de cinco décadas. [Trad. Jonas Pereira dos Santos]. Campinas/SP: Editora Psy II, 1995.

FRANKL, Viktor E. A vontade de sentido: fundamentos e aplicaçóes da logoterapia. [Trad. Ivo Studart Pereira]. São Paulo: Paulus, 2011a.

FRANKL, Viktor E. Psicoterapia y existencialismo: escritos selectos sobre logoterapia [Traducción de Antoni Martínez Riu] - 2a edición - Espańa: Herder, 2011 b.

FRANKL, Viktor E. Em busca de sentido: Um psicólogo no campo de concentração. [Trad. W. O. Schlupp e Carlos C. Aveline]. 40a ed. São Leopoldo: Sinodal; Petrópolis: Vozes, 2016a.

FRANKL, Viktor E. Teoria e Terapia das neuroses: introdução à logoterapia e análise existencial. $1^{\mathrm{a}}$ ed. [Trad. Claudia Abeling]. São Paulo: É Realizações, $2016 b$. 
FREITAS, Marina Lemos Silveira. Pedagogia do Sentido: contribuições de Viktor Frankl para a educação. Ribeirão Preto: IECVF, 2017.

FREITAS, Marina Lemos Silveira. Afrontamento e superação de crises: contribuição da Logoterapia. 2a ed. Ribeirão Preto: IECVF, 2018.

GARCÍA, Sergio Trujillo. ¿Hay un origen del proceso resiliente? Una lectura de La maravilla del dolor de Boris Cyrulnik. In: Psicogente, 14(25): pp. 164-177, 2011.

GIOVANETTI, José Paulo. Psicologia existencial e espiritualidade. In:

AMATUZZI, Mauro Martins. (Org.). Psicologia e espiritualidade. 2a ed. São Paulo: Paulus, 2008, p. 129-145.

LIMA, Ana Lúcia. Viktor Emil Frankl: um exemplo de resiliência. 2010. Disponível em: <https://www.psicologia.pt/artigos/textos/A0533.pdf>. Acesso em: 24 jul. 2020.

LUKAS, Elisabeth. Logoterapia “a força desafiadora do sentido": métodos de Logoterapia. São Paulo/SP: Ediçóes Loyola, 1989.

MELILLO, Aldo, OJEDA, Elbio Nestor Suarez. Resiliência: descobrindo as próprias fortalezas. [trad. Valério Campos] Porto Alegre: Artmed, 2005.

MORAES, Maria Cecília Leite; RABINOVICH, Elaine Pedreira. Resiliência: uma discussão introdutória. Revista Brasileira de Desenvolvimento Humano, 6 (1/2), 1013. 1996.

NIETZSCHE, Friedrich. Crepúsculo dos ídolos, ou como se filosofar com o martelo. [Trad. Paulo César de Souza]. São Paulo: Companhia do Bolso, 2017.

SILVEIRA, Daniel Rocha; MAHFOUD, Miguel. Contribuições de Viktor Emil Frankl ao conceito de resiliência. In: Estudos de psicologia, Campinas 25(4), pp. 567-576, out.-dez., 2008.

TEIXEIRA, Faustino. O potencial libertador da espiritualidade e da experiência religiosa. In: AMATUZZI, Mauro Martins. (Org.). Psicologia e espiritualidade. $2^{\text {a }}$ ed. Sáo Paulo: Paulus, 2008, pp. 13-30.

TORRALBA, Francesc Roselló. Inteligência espiritual. [Trad. João Batista Kreuch]. 2 ed. Petrópolis, RJ: Vozes, 2013.

TORRALBA, Francesc Roselló. Espiritualidade laica: uma exploración fiolosófica. In; Caminhos. Goiânia, v. 17, n. 3, p. 104-124, jul./dez. 2019.

VALLE, João Edênio dos Reis. Religião e espiritualidade: um olhar psicológico. In: AMATUZZI, Mauro Martins. (Org.). Psicologia e espiritualidade. 2a ed. São Paulo: Paulus, 2008, pp. 83-107.

Recebido: 26 de maio de 2020 .

Aprovado: 29 de julho de 2020. 